\title{
Patient Acceptability of Manual and Rotary Techniques for Instrumentation of Root Canal in Primary Teeth
}

\author{
Rahul Morankar ${ }^{1}$, Ashima Goyal ${ }^{2}$, Krishan Gauba $^{3}$, Aditi Kapur ${ }^{4}$
}

\begin{abstract}
Background: An endodontic management of the primary teeth is important considering the various untoward consequences associated with its premature loss.

Aim: To compare the patient acceptability with manual and rotary methods of root canal instrumentation during pulpectomy.

Materials and methods: Pulpectomy treatment was carried out in 60 pulpally infected the primary teeth among children aged 4-7 years. Thirty teeth were instrumented with manual and rotary methods of root canal instrumentation. Patient acceptability during instrumentation was recorded by an independent evaluator using a modified patient acceptability scale.

Results: Children accept treatment readily with manual technique; however, no statistically significant difference was observed between manual and rotary techniques of root canal instrumentation.

Conclusion: Acceptability of root canal instrumentation in children is comparable with manual and rotary techniques.

Keywords: Manual instrumentation, Patient acceptability, Primary teeth, Rotary instrumentation.

Journal of Postgraduate Medicine Education and Research (2019): 10.5005/.jp-journals-10028-1326
\end{abstract}

\section{BACKGROUND}

Advancements have been taken place in the field of pediatric endodontic in terms of techniques and materials in recent times. Root canal instrumentation is an important step of pulpectomy procedure which helps to eliminate infection from the infected irreversibly inflamed or nonvital primary teeth. ${ }^{1}$ The continuous physiological resorption in the primary teeth with an abundance of the pulpal tissue in narrow and curved roots makes a root canal instrumentation challenging. ${ }^{2}$ Both manual and rotary instrumentations are successful techniques in the permanent teeth. In the primary teeth, although instrumentation with manual stainless steel files is successful, it has been found to be time-consuming, associated with more introgenic errors such as undesirable curvatures, and makes root canal obturation difficult. ${ }^{3}$

Rotary instrumentation has several advantages in the primary teeth and in vitro studies have found it to be superior compared to manual technique in terms of parameters such as time efficiency and root canal cleaning. ${ }^{4-7}$ A randomized control trial (RCT) comparing manual and rotary methods of root canal instrumentation in primary molars had shown rotary instrumentation to be more time efficient, although long-term clinical and radiographic results were comparable. ${ }^{8}$ It has been postulated that a significantly reduced time with the rotary technique of instrumentation can influence the child behavior positively leading to better acceptance of treatment. ${ }^{9}$ Therefore, the present study was carried out for comparative evaluation of acceptance of manual and rotary methods of root canal instrumentation.

\section{Materials and Methods}

The study comprises 60 children with pulpally involved primary mandibular second molars aged 4-7 years. Children having the teeth with clinical and radiographic findings indicative of pulpectomy were selected. Those with irreversible pulpitis, necrotic pulp, sinus tract, radiolucent areas in furcation or periapical region
${ }^{1}$ Department of Oral Health Sciences Centre, Postgraduate Institute of Medical Education and Research Satellite Centre, Sangrur, Punjab, India; Department of Oral Health Sciences Centre, Postgraduate Institute of Medical Education and Research, Chandigarh, India

${ }^{2,4}$ Department of Oral Health Sciences Centre, Unit of Pedodontics and Preventive Dentistry, Postgraduate Institute of Medical Education and Research, Chandigarh, India

${ }^{3}$ Department of Oral Health Sciences Centre, Postgraduate Institute of Medical Education and Research, Chandigarh, India

Corresponding Author: Rahul Morankar, Department of Oral Health Sciences Centre, Postgraduate Institute of Medical Education and Research Satellite Centre, Sangrur, Punjab, India; Department of Oral Health Sciences Centre, Postgraduate Institute of Medical Education and Research, Chandigarh, India, Phone: +91-9855501651, e-mail: captainrahul88@gmail.com

How to cite this article: Morankar R, Goyal A, et al. Patient Acceptability of Manual and Rotary Techniques for Instrumentation of Root Canal in Primary Teeth. J Postgrad Med Edu Res 2019;53(3):118-120.

Source of support: Nil

Conflict of interest: None

were included whereas those with inadequate tooth structure, pulpal floor perforation, swelling, and excessive mobility were excluded. Children with mental disabilities, requiring sedation/ general anesthesia for management, and those with systemic diseases were also excluded from the study. An ethical clearance was obtained from the Institute Ethics Committee before the start of the study (IEC/13/3564).

Pulpectomy is a routine procedure carried out in the primary teeth. Preoperative behavior assessment was done for all the selected children using Frankl behavior rating scale on the day of procedure. ${ }^{10}$ The parents were explained about the objectives of the study, and a written informed consent was obtained from

() The Author(s). 2019 Open Access This article is distributed under the terms of the Creative Commons Attribution 4.0 International License (https://creativecommons. org/licenses/by-nc/4.0/), which permits unrestricted use, distribution, and non-commercial reproduction in any medium, provided you give appropriate credit to the original author(s) and the source, provide a link to the Creative Commons license, and indicate if changes were made. The Creative Commons Public Domain Dedication waiver (http://creativecommons.org/publicdomain/zero/1.0/) applies to the data made available in this article, unless otherwise stated. 
parents/guardian of all the participating children. The children were randomly allocated to manual and rotary instrumentation groups using sealed envelop technique of randomization. This ensures an equal chance of selection without any allocation bias.

All the children were managed using routine behavior management technique without any pharmacological means. The treatment was performed in all the selected children by the same operator in a single appointment. This helps avoid any confounding variable influencing the outcome of the study. The endodontic procedural steps including an administration of local anesthesia, rubber dam application, and root canal access preparation were same in both the study groups. They differ only in terms of means of root canal instrumentation. In the manual group, root canal instrumentation was carried out with manual stainless steel files (no. 15-30 files with 2\% taper Mani Inc. Japan) and in rotary group hyflex-CM nickel-titanium rotary files (Coltene Whaldent Inc., USA) with $4 \%$ taper were used. An independent, calibrated evaluator remains present in the operatory during the instrumentation procedure to record the patient's acceptance. It was recorded at the end of instrumentation using the modified patient acceptability scale (Table 1). ${ }^{11}$ The postinstrumentation steps including irrigation, obturation, and placement of restoration were same in both the treatment group.

\section{Statistical Analysis}

MS-Excel (Microsoft Corporation, Redmond, WA, USA) was used to enter the information in a database. The quantitative and qualitative data were analyzed statistically using Student $t$ test, Chi-square, and Fisher's exact tests where indicated. All statistical tests were twosided and performed at a significance level of $p=0.05$.

Table 1: Modified patient acceptability scale

\begin{tabular}{ll}
\hline Score & Patients acceptability of treatment \\
\hline 1 & Accepts readily \\
2 & Dislikes (as depicted by facial expression) \\
& but accepts \\
4 & Accepts with great difficulty \\
\hline
\end{tabular}

\section{Results}

Mean age of children did not differ significantly in manual and rotary instrumentation groups and it was $5.57 \pm 0.81$ and $5.57 \pm$ 0.77 , respectively. Gender too did not differ significantly between two groups. Preoperative Frankl behavior rating revealed a majority of children, 28 in the manual instrumentation group and 29 in the rotary instrumentation group had positive behavior (Table 2). An evaluation of patient acceptability during instrumentation revealed that 25 (83.3\%) and 20 (66.7\%) patients had accepted treatment readily in manual and rotary instrumentation groups, respectively (Table 3 ).

\section{Discussion}

Manual and rotary techniques of root canal instrumentation are compared in the recent past by various authors for instrumentation in the primary teeth. ${ }^{12-17}$ The various parameters of comparison include instrumentation time, obturation time, quality of obturation, an efficacy of root canal cleaning, reduction of microflora after instrumentation, dentin removal and complications. A randomozed control trial has also been conducted comparing the long-term clinical and radiographic outcomes of pulpectomy using the manual and rotary instrumentation techniques for root canal instrumentation in the primary teeth. ${ }^{8}$ However, none of the published studies in the literature had tried to evaluate and compare the patient's acceptability with manual and rotary techniques of instrumentation.

The preoperative behavior of the children included in the two study groups was recorded according to Frankl behavior rating scale. Majority of the children, 28 (93.3\%) in manual group and 29 $(96.7 \%)$ in rotary group, showed a positive behavior preoperatively on the day of treatment and only one child in each group behaved negatively. A high percentage of children with positive behavior can be attributed to the age (range 4-7 years, mean 5.57 years) of the selected children in two study groups. Moreover, prior to the treatment procedure, the selected children had visited the dental operatory for clinical and radiographic examination which might have led to increased preoperative positive behavior in the present study.

Table 2: Preoperative Frankl behavior rating of children included in the study

\begin{tabular}{|c|c|c|c|c|c|c|c|}
\hline \multirow[b]{2}{*}{ Frankl behavior rating scores } & \multicolumn{2}{|c|}{ Manual group $(N=30)$} & \multicolumn{2}{|c|}{ Rotary group $(N=30)$} & \multicolumn{2}{|c|}{ Total $(N=60)$} & \multirow[b]{2}{*}{$p$ value } \\
\hline & $N$ & $\%$ & $N$ & $\%$ & $N$ & $\%$ & \\
\hline Definitely negative & 0 & 0 & 0 & 0 & 0 & 0 & 0.60 \\
\hline Negative & 1 & 3.3 & 1 & 3.3 & 2 & 3.3 & \\
\hline Positive & 28 & 93.3 & 29 & 96.7 & 57 & 95.0 & \\
\hline Definitely positive & 1 & 3.3 & 0 & 0 & 1 & 1.7 & \\
\hline Total & 30 & 100 & 30 & 100 & 60 & 100 & \\
\hline
\end{tabular}

Table 3: Patient acceptability of manual and rotary techniques of root canal instrumentation

\begin{tabular}{|c|c|c|c|c|c|c|c|}
\hline \multirow[b]{2}{*}{ Patient's acceptability scores } & \multicolumn{2}{|c|}{ Manual group $(N=30)$} & \multicolumn{2}{|c|}{ Rotary group $(N=30)$} & \multicolumn{2}{|c|}{ Total $(N=60)$} & \multirow[b]{2}{*}{$p$ value } \\
\hline & $N$ & $\%$ & $N$ & $\%$ & $N$ & $\%$ & \\
\hline Accepts readily & 25 & 83.3 & 20 & 66.7 & 45 & 75.0 & 0.24 \\
\hline $\begin{array}{l}\text { Dislikes (as depicted by facial } \\
\text { expression) but accepts }\end{array}$ & 3 & 10.0 & 8 & 26.7 & 11 & 18.3 & \\
\hline Accepts with difficulty & 2 & 6.7 & 2 & 6.7 & 4 & 6.7 & \\
\hline Does not accept & 0 & 0 & 0 & 0 & 0 & 0 & \\
\hline Total & 30 & 100 & 30 & 100 & 60 & 100 & \\
\hline
\end{tabular}


The results revealed that a trend toward greater acceptability of manual technique was observed although it was not statistically significant when compared with rotary technique of root canal instrumentation. A greater percentage of children (83.3\%) in the manual group readily accept the technique compared to the rotary instrumentation group (66.7\%). According to Finn, an inverse relationship existed between the cooperation of the patients and the length of time spent in a dental chair. ${ }^{9}$ In the literature, it has been postulated that the rotary instrumentation takes significantly less time for instrumentation and expected to be associated with the more positive behavior of the patient. ${ }^{18}$ However, a slightly better acceptability with the manual technique in the present study can attribute to the disadvantages of rotary technique that include (1) fear of handpiece and (2) rotary files clearly visible to the patient compared to the manual technique. Although less instrumentation time favors a better cooperation with rotary technique, overall, there was no statistically significant difference observed between two groups.

\section{Conclusion}

The results of the present study revealed that the manual and rotary techniques of root canal instrumentation in the primary teeth were comparable in terms of patient's acceptance.

\section{Informed Consent}

Informed consent was obtained from all individual participants/ parents included in the study.

\section{Authorship}

This manuscript represents valid work and that neither this manuscript nor one with substantially similar content under the present authorship has been published or is being considered for publication elsewhere and the authorship of this article will not be contested by anyone whose name(s) is/are not listed here, and that the order of authorship as placed in the manuscript is final.

\section{References}

1. Moghaddam KN, Mehran M, et al. Root canal cleaning efficacy of rotary and hand files instrumentation in primary molars. Iran Endod J 2009;4:53-57.

2. Dummett CO, Kopel HM. Pediatric endodontics. In: Ingle JI, Bakland LK. ed. Endodontics, 5th ed., London: BC Decker Inc. Hamilton; 2002. pp. 861-902.

3. Walton RE, Torabinejad M. Principles and practice of endodontics, 3rd ed., Saunders Company Inc.; 2002. p. 222.
4. Silva LA, Leonardo MR, et al. Comparison of rotary and manual instrumentation techniques on cleaning capacity and instrumentation time in deciduous molars. J Dent Child 2004;71:45-47.

5. Bahrololoomi $Z$, Tabrizizadeh $M$, et al. In vitro comparison of instrumentation time and cleaning capacity between rotary and manual preparation techniques in primary anterior teeth. J Dent Tehran Univ Med Sci 2007;4:59-62.

6. Kummer TR, Calvo MC, et al. Ex vivo study of manual and rotary instrumentation techniques in human primary teeth. Oral Surg Oral Med Oral Pathol Oral Radiol Endodontol 2008;105:84-92. DOI: 10.1016/j.tripleo.2007.12.008.

7. Madan N, Rathnam A, et al. K-file vs ProFiles in cleaning capacity and instrumentation time in primary molar root canals: an in vitro study. J Indian Soc Pedod Prev Dent 2011;29:55-61. DOI: 10.4103/09704388.79907.

8. Morankar R, Goyal A, et al. Manual vs rotary instrumentation for primary molar pulpectomies-A 24 months randomized clinical trial. Pediatr Dent J 2018;28(2):96-102. DOI: 10.1016/j.pdj.2018.02.002.

9. Finn SB. Child management in the dental office. In: Finn SB. ed. Clinical Pedodontics. Philadelphia: WB saunders; 1998. p. 39.

10. American Academy on Pediatric Dentistry Clinical Affairs CommitteeBehavior Management Subcommittee, American Academy on Pediatric Dentistry Council on Clinical Affairs. Guideline on behavior guidance for the pediatric dental patient. Pediatr Dent 2008;30(7):125-133.

11. Pandit UA, Collier PJ, et al. Oral transmucosal midazolam premedication for preschool children. Can J Anesthesia 2001;48(2): 191-195. DOI: 10.1007/BF03019734.

12. Musale PK, Mujawar SA. Evaluation of the efficacy of rotary vs. hand files in root canal preparation of primary teeth in vitro using CBCT. Eur Arch Paediatr Dent 2014 Apr;15(2):113-120. DOI: 10.1007/s40368013-0072-1.

13. Katge $F$, Patil $D$, et al. Comparison of instrumentation time and cleaning efficacy of manual instrumentation, rotary systems and reciprocating systems in primary teeth: an in vitro study. J Indian Soc Pedod Prev Dent 2014;32(4):311-316. DOI: 10.4103/0970-4388.140957.

14. Barr ES, Kleier DJ, et al. Use of nickel-titanium rotary files for root canal preparation in primary teeth. Pediatr Dent 2000;22(1):77-78.

15. Romero TO, Gonzalez VM. Comparison between Rotary and Manual Techniques on Duration of Instrumentation and Obturation Times in Primary Teeth. J Clin Pediatr Dent 2011;35(4):359-364. DOI: 10.17796/ jcpd.35.4.8k013k21t39245n8.

16. Subramaniam $P$, Tabrez TA, et al. Microbiological assessment of root canals following use of rotary and manual instruments in primary molars. J Clin Pediatr Dent 2013 Winter;38(2):123-127. DOI: 10.17796/ jcpd.38.2.j84265t82u60271u.

17. Parashos P, Gordon I, et al. Factors influencing defects of rotary nickel-titanium endodontic instruments after clinical use. JOE 2004;30:722-725. DOI: 10.1097/01.DON.0000129963.42882.C9.

18. Morankar R, Goyal A. Rotary Instrumentation in Primary Teeth: A Review. Int Healthcare Res J 2017;1(5):10-16. DOI: 10.26440/ ihrj/01_05/102. 